\title{
China Agricultural Information Efficiency Motivation Variance
}

\author{
Analysis \\ HuiPo Wang ${ }^{1}$, LiPeng Zhang ${ }^{1}$, XiaoBo $\mathrm{Gu}^{3}$ and Bo Lu ${ }^{1,2, \mathrm{a}^{*}}$ \\ ${ }^{1}$ College of Economy and Management, Dalian University, Dalian, China, 116622 \\ ${ }^{2}$ School of Management, Chinese Academy of Sciences, Beijing, China, 100190 \\ ${ }^{3}$ College of City and Environment, Jiangsu Normal University, Xuzhou, China, 221116 \\ aEmail: lubo_documents@hotmail.com
}

Keywords: Agricultural informatization; Efficiency; DEA; Indexes system; Data analyze

\begin{abstract}
At the end of 2014, the National Land survey data show that China arable land is gradually reducing and per capita cultivated land is less than half of the world's average level. Modern society is the information age. Agriculture has transferred from the original agriculture into information agriculture. To build a well-off society, agricultural informatization efficiency research has important significance for China developing country and agricultural country. In this paper, through constructing agricultural informationization input and output efficiency indicator system and combining with the statistical data from 2009 to 2013, we analyze the agricultural informationization efficiency of 31 provinces, cities and autonomous regions of our country using DEA method. Respectively from the eastern, central and western regions to select two representative cities: Beijing, Shandong, Heilongjiang, Shanxi, Tibet and Xinjiang, we analyze the efficiency change. The result shows that the efficiency values in eastern regions are stable and the central regions have great fluctuations and the western regions steadily rise.
\end{abstract}

\section{Research background of agricultural informatization efficiency}

Cultivated land is not only the foundation of the national economy, but also bear the national food security, ecological security and social stability [1-4]. Our country cultivated land is in the decline stage at present. In order to build a moderately prosperous society this would require the efficiency improvement. That is to say, the core issue of economic and social development of our country in the next decade or even two decades is efficiency. With the development of social modernization and informatization, our country agriculture gradually transfers from primitive agriculture to the informatization agriculture. Agricultural informationization is to use all sorts of agricultural information technology widely in the whole process of agricultural production, management and service field. Agricultural informationization makes agricultural production highly informationization, intellectualized in order to save the cost of labor and improve agricultural productivity level. Agriculture informatizationhas become an important index of the core competitiveness in a country or a region[5].With the development and mature of 4G technology and Internet technology, they also brought further opportunities for the development of agricultural informationization. Therefore, for developing China which dominated by agriculture, the research of agricultural informatization efficiencyof 31 provinces, cities and autonomous regions is particularly important in front of severe reality in the information age. 


\section{The research methods (DEA)}

In the late $1970 \mathrm{~s}$, with the development of data envelopment (DEA) method, technical efficiency measurement was being taken seriously. DEA method is based on the Farrell mathematical measuring method, put forward by Debyeu et al [6] and extended by Fare [7-8].The agricultural informationization efficiency of China's 31 provinces, cities and autonomous regions is the same type of a multiple input and multiple output system evaluation. Combining with the advantage of DEA method, the article adopts the DEA method to evaluate the agricultural informationization efficiency of various provinces, cities and autonomous regions and makes dynamic analysis.

\section{Construct the agricultural informatization efficiency indicator system}

Chinaagriculture is characterized by a high degree of dispersion, all kinds of variety, small family business and present non-standard development. As a result, there is a certain difficulty in the selection of agricultural informatization measurement indicators. Of course, the availability of data also limits the selection of indicators. So scholars from all over the world had different opinion in constructing agricultural informatization measurement indicators. Wang yong, Wang Wen-liang's (2013) "Henan agricultural informatization level evaluation" proposed five first level indicators and fourteen secondary indicators [9]. Zhu Zhaoping, Wang Sheng-lin (2014) raised the five benchmark indicators and twenty layers indicators involved in "Agricultural informatization and its indicators evolution" [10]. Considering the construction of agriculture informatization efficiency measurement index system from previous scholars, this paper constructs agricultural informatization efficiency input and output indicator system such as table 1 and table2:

Table 1 The input index in agricultural informatization efficiency evaluation system

\begin{tabular}{|c|c|c|}
\hline No & Input indexes & Index explanations \\
\hline 1 & $\begin{array}{l}\text { The number of TV in every hundred rural } \\
\text { households }\end{array}$ & $\begin{array}{l}\text { Reflect the application level of rural TV } \\
\text { network construction }\end{array}$ \\
\hline 2 & $\begin{array}{l}\text { The number of computers in every hundred } \\
\text { rural households }\end{array}$ & $\begin{array}{l}\text { Reflect the popularity of computers in } \\
\text { rural }\end{array}$ \\
\hline 3 & $\begin{array}{l}\text { The number of telephone in every hundred } \\
\text { rural households }\end{array}$ & $\begin{array}{l}\text { Reflect the application level of rural } \\
\text { telephone network construction }\end{array}$ \\
\hline 4 & $\begin{array}{l}\text { The proportion of agricultural employment } \\
\text { personnel }\end{array}$ & Measure rural informatization talents \\
\hline 5 & $\begin{array}{l}\text { The number of people of high school or } \\
\text { above in every hundred rural household } \\
\text { labor }\end{array}$ & $\begin{array}{l}\text { Reflect the agricultural information } \\
\text { accept ability }\end{array}$ \\
\hline 6 & $\begin{array}{l}\text { Investment of rural agricultural } \\
\text { informatization }\end{array}$ & $\begin{array}{l}\text { The economic conditions of } \\
\text { Agricultural information technology } \\
\text { development }\end{array}$ \\
\hline 7 & Information index & $\begin{array}{l}\text { Reflect the farmers' information } \\
\text { consumption ability }\end{array}$ \\
\hline 8 & The number of township in rural & $\begin{array}{l}\text { Describe an overview of information } \\
\text { resources }\end{array}$ \\
\hline
\end{tabular}


Table2 The output index in agricultural informatization efficiency evaluation system

\begin{tabular}{|c|c|c|}
\hline No & Output indexes & Index explanations \\
\hline 1 & Per capita net income of rural residents & Reflect the agricultural informationization \\
\hline 2 & The added value in agriculture & economic returns \\
\hline 3 & $\begin{array}{l}\text { The ratio of urban and rural residents' } \\
\text { income level }\end{array}$ & Reflect the agricultural informationization \\
\hline 4 & $\begin{array}{l}\text { The ratio of urban and rural residents' } \\
\text { consumption level }\end{array}$ & society benefit \\
\hline
\end{tabular}

\section{Data analyze of agricultural informatization efficiency}

In this paper, by agricultural informationization input and output efficiency indicator system and combining with the statistical data from 2009 to 2013, we analyze the agricultural informationization efficiency of 31 provinces, cities and autonomous regions of our country using CCR-O Model in DEA method. Respectively from the eastern, central and western regions to select two representative and Change significantly cities: Beijing, Shandong, Heilongjiang, Shanxi, Tibet and Xinjiang, we analyze the efficiency change. The result as shown in Figure.1:
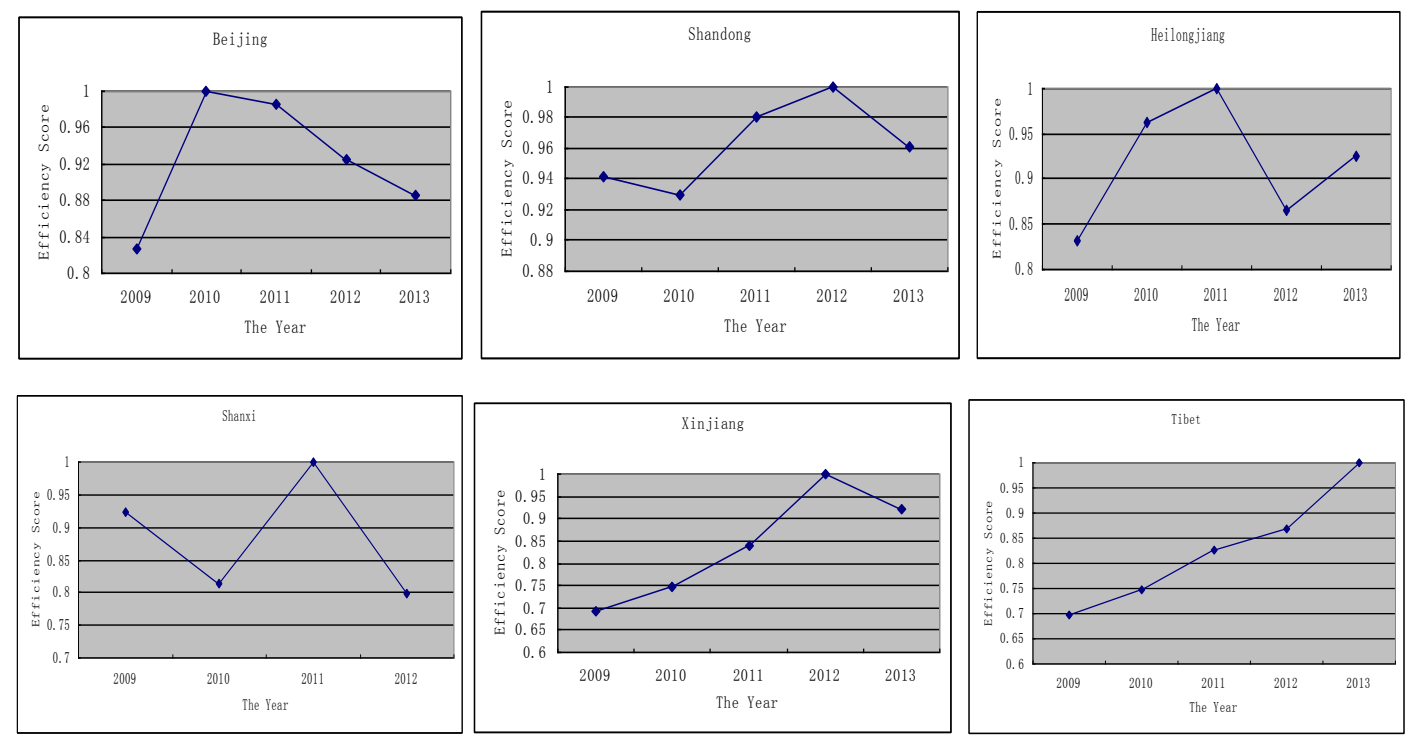

Figure.1The efficiency value in every region

We can see from Fig.1, the eastern regions including Beijing and Shandong have very high agricultural informationization efficiency value. The efficiency values in all years are more than 0.85 and the variation of efficiency values is stable. This is because with the rapid development of the eastern region, these regions have more investment and their equipment is complete.From 2009 to 2013, the agricultural informationization efficiency values in central region of China fluctuates greatly. This is because When the investment is bigger, the efficiency will be high. Overall, the efficiency value in the western regions has been steadily rising. The development of the western region, provide motivation for western areas to enhance the agricultural informatization efficiency.

\section{Conclusions}

In this paper, using DEA methods and models, we make agricultural informatization efficiency dynamic analysis in 31 provinces, cities and autonomous regions of our country from 2009 to 2013, combined with the input and output indexes of agricultural informatization efficiency. From the analysis results, we can know that the agricultural informatization efficiency of eastern regions are stable and the efficiency score has been in a higher level. In the central regions, the agricultural informatization efficiency values have great fluctuations. And the efficiency of western regions has been steadily rising. 


\section{Acknowledgements}

This work was supported by the National Natural Science Foundation of China (71372120); the National Science Foundation for Young Scientists of China (41101158); Liaoning Provincial Natural Science Foundation (2013020006);2014 Liaoning BaiQianWan Talents Program (Third Category); Liaoning Social Science Planning Fund Plan (L14CJY041); 2014 Dalian Science and technology project from Dalian Municipal Science and Technology Bureau(2014D11ZC117);Liaoning Provincial Education Department (W2012246); National Science Foundation for Post-doctoral Scientists of China (2014M550084); Scientific Research Foundation for the Returned Overseas Chinese Scholars, State Education Ministry; Dalian Jinzhou New District Science and technology project (2013-2kx2-001)..

\section{References}

[1]CaiYunlong, Fu Zeqiang. To improve land productivity is the ultimate - re-recognition of cultivated land protection.ChinaLand, 2002, (10):11-13

[2]Yu Fengqing, CaiYunlong. Cultivated land resource value reconstruction and agricultural subsidies - a solution to the problem of "agriculture, rural areas and farmers" policy orientation.ChinaLand Science, 2004, 18(1):18-23

[3]Yu Fengqing, CaiYunlong. Cultivated land resource valueevalution.ChinaLand Science ,2003 , 17(3):3-9

[4]Ding Hongjian, Wu Cifang, Liang Like. The concept of cultivated land protection innovation research.ChinaLand Science, 2002, 16(4):14-19

[5]Ding li, Li Bengjun, TianZhenqiang.Henan municipal regional agriculture informationization development level evaluation and analysis.Journal of Henan agricultural university, 2010,44 (3), 343-347

[6]Debreu,G.Thecoefficientofresourceutilization.Econometrica1951, 19:273-292.

[7]Shephard,R.W.CostandProductionFunctions.PrincetonUniversityPress,Princeton,N.J., 1953

[8]Shephard,R.W.TheTheoryofcostandProductionFunctions.PrincetonUniversityPress,Princeton, N.J., 1970

[9]Wang yong, Wang Wen-liang. Henan agricultural informatization level evaluation.Technical economy, 2013, 32(4):85-88

[10]Zhu Zhaoping, Wang Sheng-lin.Gansu province agricultural informatization evaluation index system research. Journal of library and ingormation science in agriculture, 2014, 26(4):16-18 